\title{
Percutaneous coronary intervention of the left main coronary artery in a patient with extrinsic compression caused by massive pulmonary artery enlargement
}

\author{
Khaled F. Salhab, MD, ${ }^{\mathrm{a}}$ Adil H. Al Kindi, MD, ${ }^{\mathrm{a}}$ Stephen G. Ellis, MD, ${ }^{\mathrm{b}}$ Neha Lad, MD, ${ }^{\mathrm{a}}$ and \\ Lars G. Svensson, MD, $\mathrm{PhD}^{\mathrm{a}}$
}

Extrinsic compression of the left main coronary artery (LMCA) by a dilated pulmonary artery (PA) is a rare condition that is seen in patients with severe pulmonary hypertension. The optimal treatment of this condition remains unclear. We report a patient who presented with acute coronary syndrome and was treated with LMCA stent implantation.

\section{CLINICAL SUMMARY}

A 64-year-old woman with a history of lupus anticoagulant, heparin-induced thrombocytopenia, recurrent pulmonary emboli, and severe chronic pulmonary hypertension who was receiving treprostinil injections presented with angina and was found to have a non-ST-segment myocardial infarction. Her surgical history included pulmonary thromboendarterectomy and placement of a vena cava filter.

\footnotetext{
From the Department of Thoracic and Cardiovascular Surgery a and Department of Cardiovascular Medicine, ${ }^{\mathrm{b}}$ Cleveland Clinic, Cleveland, Ohio.

Disclosures: Authors have nothing to disclose with regard to commercial support.

Received for publication July 15, 2012; accepted for publication July 30, 2012; available ahead of print Aug 27, 2012.

Address for reprints: Lars G. Svensson, MD, PhD, Division of Thoracic and Cardiovascular Surgery, Cleveland Clinic, 9500 Euclid Avenue/Desk J4-1, Cleveland, OH 44195 (E-mail: svenssl@ccf.org).

J Thorac Cardiovasc Surg 2012;144:1517-8

$0022-5223 / \$ 36.00$

Copyright (C) 2012 by The American Association for Thoracic Surgery

http://dx.doi.org/10.1016/j.jtcvs.2012.07.086
}

She also was undergoing evaluation for a heart-lung transplant before her admission. A transthoracic echocardiogram showed normal left ventricular systolic function, mildly depressed right ventricular function, an estimated right ventricular systolic pressure of $71 \mathrm{~mm} \mathrm{Hg}$, and a massively dilated PA at $8 \mathrm{~cm}$.

Because of the patient's symptoms, she underwent urgent coronary angiography. Coronary angiography of the LMCA showed a significant filling defect. The rest of the coronary arteries were normal. Given her hypercoagulable history, this was thought to be a thrombus, and a bivalirudin infusion was administered. An intra-aortic balloon pump also was inserted, and she was transferred to the coronary care unit.

Further workup included coronary computed tomographic angiography that revealed significant narrowing of the LMCA secondary to extrinsic compression by the massively enlarged main pulmonary trunk, with no definite thrombus identified in the LMCA (Figure 1, A, arrow).

A surgical consultation was obtained. However, given the prohibitive operative risk associated with coronary artery bypass surgery in this patient, the decision was made to proceed with percutaneous coronary intervention (PCI) for the treatment of the LMCA obstruction and symptomatic relief.

Pre-PCI angiography revealed severe stenosis of the LMCA with a "slit-like" appearance of almost the entire LMCA best seen on left anterior oblique views with cranial

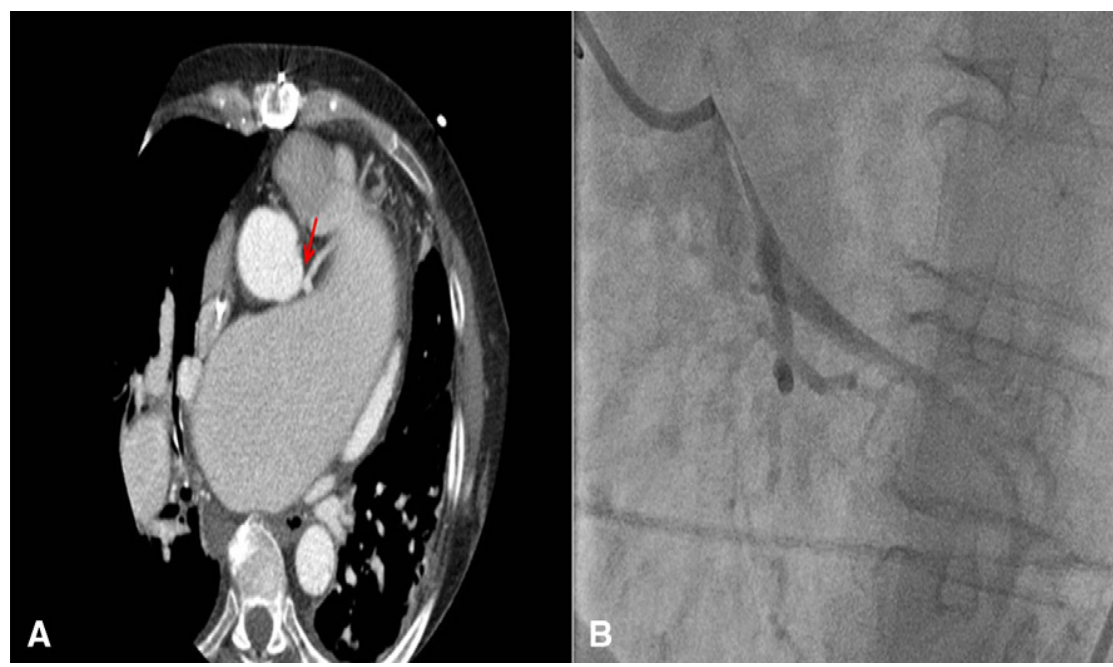

FIGURE 1. Coronary computed tomographic angiography (A) showing extrinsic compression of the LMCA by a massively enlarged PA (arrow), and (B) coronary angiography showing severe stenosis of the LMCA with a "slit-like" appearance. 


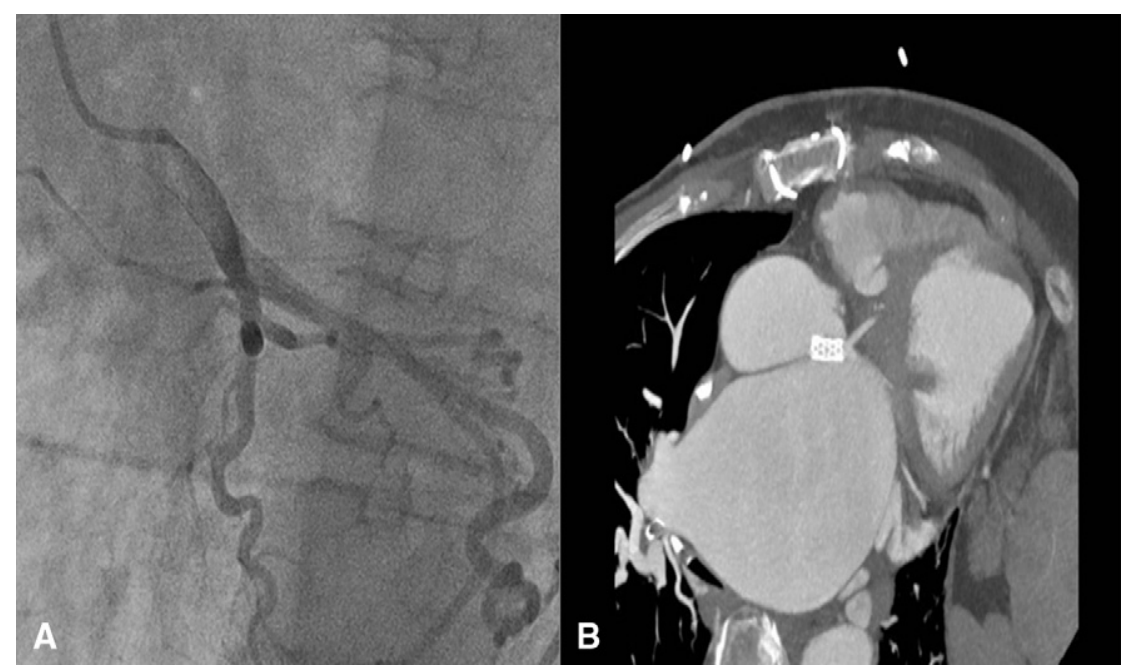

FIGURE 2. Coronary angiography (A) showing excellent LMCA stent placement with no residual stenosis, and (B) computed tomographic angiography showing a widely patent LMCA stent with no significant compression.

angulation (Figure 1,B). The LMCA was stented with a Genesis (Cordis Corp, Warren, NJ) $6.0 \times 18$-mm baremetal stent deployed at 12 atm. Post-PCI intravascular ultrasonography confirmed good expansion and stent placement, and angiography confirmed excellent results with zero residual stenosis (Figure 2, A). The patient recovered and was dismissed 8 days after intervention. Coronary computed tomographic angiography before dismissal showed a widely patent LMCA stent with no significant compression (Figure 2, $B$ ).

\section{DISCUSSION}

Extrinsic compression of the LMCA by a massively dilated PA is a rare entity, with only a few reported cases in the literature. This is usually seen in individuals with severe long-standing pulmonary hypertension. ${ }^{1}$ Given the anatomic proximity of LMCA to the PA, massive enlargement results in compression of the LMCA and may lead to myocardial ischemia, infarction, and even sudden death. This has been observed when the main PA diameter exceeds $40 \mathrm{~mm}^{2}$

The treatment algorithm for this rare entity is often challenging, and the role of surgery in such patients is somewhat controversial. A conservative approach may be preferable particularly in asymptomatic patients, whereas a more aggressive approach is usually warranted in symptomatic patients.

Our patient was clearly symptomatic and presented with myocardial infarction from LMCA extrinsic compression. However, because of the prohibitive morbidity and mortality associated with surgery in patients with severe pulmonary hypertension and the increased risk associated with a reoperation, LMCA stenting was favored for revascularization.

The first successful LMCA stent placement was performed by Rich and colleagues ${ }^{3}$ in 2 patients with LMCA compression and pulmonary hypertension. Since then, there have been only 6 other cases reported in the literature, with our case being the second report of stent implantation for treatment of a patient with non-ST-segment myocardial infarction caused by LMCA extrinsic compression from PA enlargement. ${ }^{4,5}$

\section{CONCLUSIONS}

Little is known about the long-term outcome of LMCA stenting done for extrinsic compression, and treatment of this condition should be individualized. However, reinforcing the wall of the LMCA with a stent is a novel approach that allows for symptomatic relief while avoiding the major complications associated with surgery in certain high-risk patients.

\section{References}

1. Sakuma M, Demachi J, Suzuki J, Nawata J, Takahashi T, Shirato K. Proximal pulmonary artery aneurysms in patients with pulmonary artery hypertension: complicated cases. Intern Med. 2007;46:1789-93.

2. Mesquita SM, Castro CR, Ikari NM, Oliveira SA, Lopes AA. Likelihood of left main coronary artery compression based on pulmonary trunk diameter in patients with pulmonary hypertension. Am J Med. 2004;116:369-74.

3. Rich S, McLaughlin VV, O'Neill W. Stenting to reverse left ventricular ischemia due to left main coronary artery compression in primary pulmonary hypertension. Chest. 2001;120:1412-5.

4. Caldera AE, Cruz-Gonzalez I, Bezerra HG, Cury RC, Palacios IF, Cockrill BA, et al. Endovascular therapy for left main compression syndrome. Case report and literature review. Chest. 2009;135:1648-50.

5. Lindsey JB, Brilakis ES, Banerjee S. Acute coronary syndrome due to extrinsic compression of the left main coronary artery in a patient with severe pulmonary hypertension: successful treatment with percutaneous coronary intervention. Cardiovasc Revasc Med. 2008;9:47-51. 